
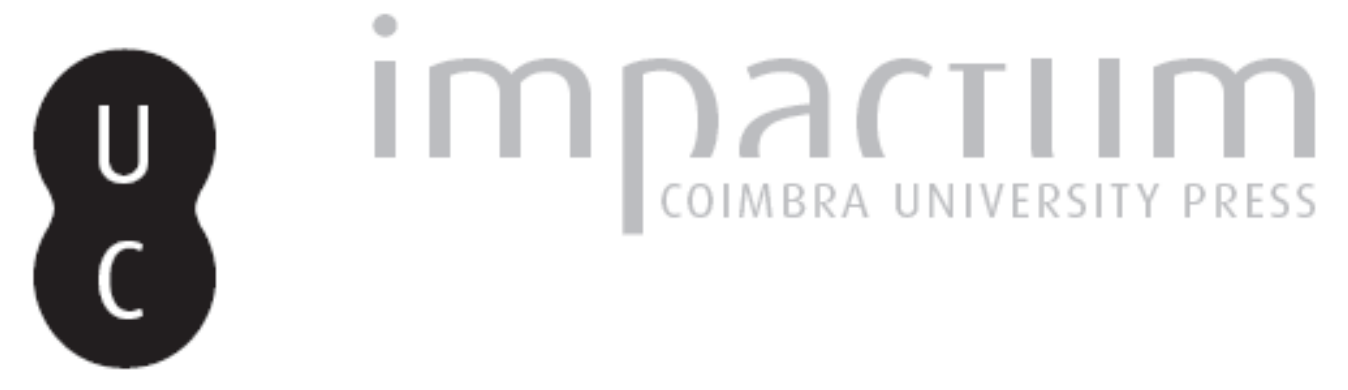

\title{
[Recensão a] NICOLAS RICHER (2012), La Religion des Spartiates. Croyances et cultes dans l'Antiquité
}

\author{
Autor(es): Horta, Martim Aires
}

Publicado por: Centro de História da Universidade de Lisboa

URL persistente:

URI:http://hdl.handle.net/10316.2/38936

DOI:

DOI:http://dx.doi.org/10.14195/0871-9527_24_12

Accessed : $\quad$ 26-Apr-2023 08:51:04

A navegação consulta e descarregamento dos títulos inseridos nas Bibliotecas Digitais UC Digitalis, UC Pombalina e UC Impactum, pressupõem a aceitação plena e sem reservas dos Termos e Condições de Uso destas Bibliotecas Digitais, disponíveis em https://digitalis.uc.pt/pt-pt/termos.

Conforme exposto nos referidos Termos e Condições de Uso, o descarregamento de títulos de acesso restrito requer uma licença válida de autorização devendo o utilizador aceder ao(s) documento(s) a partir de um endereço de IP da instituição detentora da supramencionada licença.

Ao utilizador é apenas permitido o descarregamento para uso pessoal, pelo que o emprego do(s) título(s) descarregado(s) para outro fim, designadamente comercial, carece de autorização do respetivo autor ou editor da obra.

Na medida em que todas as obras da UC Digitalis se encontram protegidas pelo Código do Direito de Autor e Direitos Conexos e demais legislação aplicável, toda a cópia, parcial ou total, deste documento, nos casos em que é legalmente admitida, deverá conter ou fazer-se acompanhar por este aviso.

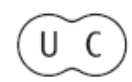




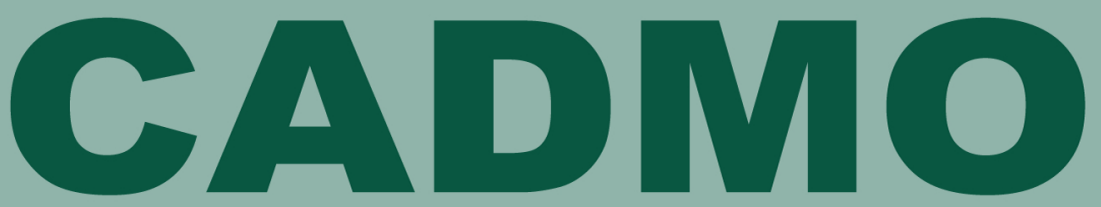

Revista de História Antiga

\section{Centro de História da Universidade de Lisboa}

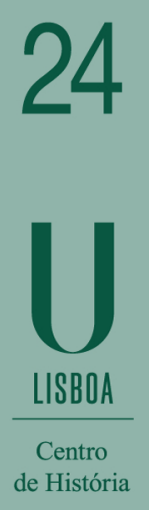

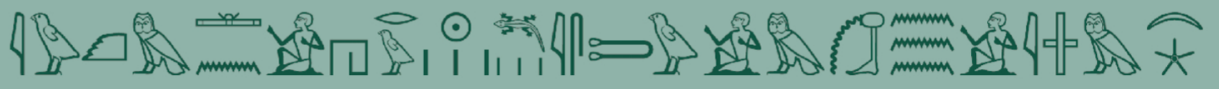


MHNIN AEI $\Delta$ E $\Theta E A ~ \Pi H \Lambda H I A \Delta E \Omega$ 
do personagem. Além da etimologia, diz o autor, o discurso do próprio demiurgo evoca os Trabalhos: «la descrizione della potenza del demiurgo nel discorso agli dei è construita sul modelo dell'aretalogia di Zeus negli Erga tramite puntuali accordi nella dizione» (p. 178). O que faz Platão, em suma, é «attraverso l'etimologia [...] recupera[re] il contributo di Esiodo» e a ele conferir, para além da esfera etimológica, «una funzione ideologica nello sviluppo complessivo del cosmo richiamato dal Timeo al Crizia» (p. 175).

Il Poeta e il Demiurgo é, sem dúvida alguma, livro de enorme erudição: é escrito por um especialista para especialistas. Sua farta bibliografia e as numerosas notas de rodapé (666 no total) abrem uma série de veredas para quem deseja aprofundar suas pesquisas, ao mesmo tempo que apresentam panorama bastante completo daquilo que já foi dito sobre o assunto.

\section{Hugo Langone}

NICOLAS RICHER (2012), La Religion des Spartiates. Croyances et cultes dans l'Antiquité. (Histoire 113) Paris, Les Belles Lettres, 816 pp. ISBN 978-2-251-38113-8 (55.00€).

$\mathrm{Na}$ sequência dos seus trabalhos nas últimas décadas, Nicolas Richer apresenta uma obra sobre o assunto de que é académico de referência, o sistema religioso de Esparta. A monografia, contudo, não procura ser uma síntese regional orientada em torno dos conceitos fundamentais de culto, divindade e função desdobrados sobre a geografia da Lacónia de acordo com a documentação existente. Valoriza-se, essencialmente, a comunidade dos homoioi como eixo condutor do raciocínio monográfico e chave preferencial para a interpretação dos fenómenos religiosos historiáveis. Para Richer, são as relações permanentes entre o divino e as dinâmicas do grupo que organizam os elementos do rito, as narrativas mitológicas e estruturam as crenças. As respostas encontram-se na interpretação dos comportamentos, ritmos do quotidiano e da vivência de cada um enquanto espartano. A organização dos conteúdos obedece de uma forma clara a este programa de exegese, pelo que é evitada a exposição extensiva dos cultos do terrtório, sendo somente alguns escolhidos para estudos de caso quando enquadrados no nexo da proposta. 
Tal orientação não significa que esta obra seja, de forma alguma, posta em causa como trabalho de referência. Richer propõe um discurso coerente que concilia as problemáticas introdutórias de cada tema com as suas próprias hipóteses, fundamentando-se numa extensa bibliografia e num completo conjunto de notas. É trabalhado um largo espectro de fontes, embora seja manifesta uma relevante preferência, talvez necessária, pelos testemunhos de Xenofonte e Platão, sendo que, quanto ao último, Richer procura inferir referências ao espírito religioso e comportamento dos Espartanos nas construções da cidade ideal, principalmente a partir do quadro apresentado em As Leis. Quanto ao tratamento de fontes tardias, como Pausânias e Luciano, recebem uma análise cuidada para assegurar a validade dos dados fornecidos em eventuais projecções das suas informações para o período clássico e arcaico.

A obra inicia com uma listagem possível de cultos mais importantes, referenciados de acordo com o suposto impacto na vida de cada espartano e na comunidade por três categorias: iniciação, paz e guerra. Segue-se aquele que talvez seja o mais interessante capítulo da obra, dedicado à deificação dos chamados pathēmata, abstracções que Richer define como o conjunto de sentimentos trabalhados e revalorizados pela sociedade espartana na procura de um certo ideal de auto-controlo, como Aidos, Hypnos ou Phobos. A propósito deste fenómeno, o autor apresenta uma série de noções essenciais para a vivência religiosa da comunidade, aludidas recorrentemente ao longo da obra. Encontramos assim a ideia de benefício público do comportamento correcto face aos deuses, estruturado em torno da exposição da ideologia cívica e das dinâmicas de expectativa social de disciplina. Tais atitudes complementariam a procura da andragathia na formação de cada cidadão, ao valorizar determinados comportamentos em reacção às personificações. É avançada a hipótese de esta dinâmica ter resultado de uma inovação do século VI a.C. numa suposta reforma de Quílon, em seguida aplicada num estudo de caso sobre o culto de Phobos, único na religião grega.

A terceira secção, dedicada aos ritos funerários, continua uma abordagem semelhante ao tratado para os pathēmata, articulando a procura da andragathia na organização e entendimento das práticas. Se uma certa diferenciação em vida pode ser alcançada pelo valor individual ao serviço da polis, esta separaria formalmente cada membro da comunidade aquando da sua morte: a forma de enterramento e o tipo de monumento fúnebre afasta os que cairão no esquecimento 
dos que merecem permanecer na memória. Neste sentido, o autor propõe que em Esparta existiria uma clara hierarquia, com várias categorias intermédias, determinante para associar elementos rituais e suportes materiais funerários a cada morto. Segue-se um capítulo dedicado à relação entre comunidade e território, cuja tese central se foca na procura de garantia da protecção divina em função do controlo desse mesmo espaço: os deuses de Esparta protegem a Lacónia, devem ser levados com os próprios Espartanos nas expedições fora das fronteiras que, contudo, nunca os libertam de observar as devidas honras às divindades locais.

Em seguida, Richer desenvolve uma hipótese sobre a religiosidade espartana, em que lê uma aparente particularidade na associação de elementos do sistema em pares (de divindades, santuários ou estátuas de culto), procurando estabelecê-la como prova de uma tendência para a reflexão dicotómica característica da mentalidade dos homoioi. No entanto, é evidente a dificuldade sentida em separar os exemplos que oferece de formas elementares da língua e cultura grega, e o próprio autor admite que, a existir, não seria nem original nem exclusiva. Os dois capítulos seguintes focam-se nos homens e mulheres como actores do culto, abordando a questão dos critérios de participação nos ritos pelo prisma do paradigma da utilidade pública do acto religioso: às famílias tidas como tradicionalmente propensas a relações com determinadas divindades são reconhecidos privilégios de hereditariedade, a fim de manter a protecção divina que prestam à cidade. Também é desenvolvido o processo de institucionalização da consulta oracular em Esparta, e discutida a extensão da participação das mulheres na vida religiosa com base na documentação existente.

Seguem-se quatro capítulos que podem ser vistos como estudos de caso, focando-se nas três principais festas - Jacíntias, Gimnopédias e Carneias - e nos combates dos jovens em Platanistes. $\mathrm{O}$ autor aborda, para cada festividade, as principais teorias e os testemunhos de que dispomos para as trabalhar, e desenvolve, fundamentalmente, quatro tópicos - estrutura dos ritos, espectro de participação, enquadramento no calendário, significados do conjunto - antes de propor as suas interpretações. No primeiro caso, assume a tese de que as Jacíntias seriam uma celebração essencialmente espartana (deixando em segundo plano eventuais especificidades de Amiclas) e propõe uma componente dionisíaca substancial no culto. Quanto às Gimnopédias, prefere, à leitura de um nexo iniciático, a possibilidade de que o rito preservaria a memória de uma batalha na celebração do deus; 
e sobre as Carneias, trabalha a proposta de uma entidade pré-dórica teriomórfica que teria sido sincretizada na figura de Apolo Karneios. Quanto aos combates, dedica uma longa reflexão sobre a validade das fontes tardias e as condições para que essas informações possam ser atribuídas a períodos anteriores da história de Esparta. O recuo leva o autor a construir paralelos com práticas romanas, macedónicas e védicas, concluindo pela hipótese de sobrevivência de um arquétipo estrutural em torno da legitimação real da diarquia espartana pelo combate, cristalizado como ritual.

A obra termina com uma proposta de organização do calendário religioso da cidade, na sequência das análises precedentes. No geral, Richer parece aceitar a imagem de que os Espartanos seriam particularmente pios entre os gregos, percepção reforçada com o enfoque nos comportamentos e na ideologia dos homoioi. Consequentemente, Periecos e Hilotas, tal como outras populações sujeitas da Lacónia, só pontualmente são aludidas enquanto participantes nas festas que, para o autor, não Ihes pertencem na totalidade. Contudo, lembremos, toda a monografia ensaia, abertamente, uma interpretação de conjunto a partir das dinâmicas de um grupo específico da comunidade. Por isso, quando questionamos a validade de tal opção, encontramo-nos nos limites da programática avançada.

Martim Aires Horta

STEPHANIE PAUL (2013), Cultes et sanctuaires de l'île de Cos. (Kernos Supplément 28). Liège, Presses Universitaires de Liège, 442 pp. ISBN 978-2-87562-029-3 (40.00€).

Stephanie Paul apresenta uma monografia regional sobre a religiosidade da ilha de Cós, na sequência da sua tese de doutoramento, que revê completamente o estado deste assunto desde os esforços de Sherwin-White (1978). Trata-se de uma obra dotada de extensas e completas referências documentais, que aproveita na totalidade as potencialidades dos testemunhos epigráficos, fundamentais numa comunidade em relação à qual as fontes literárias não nos elucidam com particular profundidade e que, como a maioria das ilhas do Egeu, fica de fora do percurso de Pausânias. Este esforço inclui, sublinhe-se, os primeiros resultados da revisão da totalidade do corpus epigráfico da ilha nas Inscriptiones Graecae (Vol. 12/4, fasc. 1, 2010), que 